\title{
IMAGE OF THE SURFACE OF GAS TURBINE BLADE AS A DIAGNOSTIC SIGNAL
}

\author{
Józef BŁACHNIO*, Iwona ZABROCKA** \\ *Bialystok Technical University, Faculty of Mechanical Engineering, ul. Wiejska 45C, 15-351 Bialystok, Poland \\ *student, Bialystok Technical University, Faculty of Mechanical Engineering, ul. Wiejska 45C, 15-351 Bialystok, Poland \\ j.blachnio@pb.edu.pl, i.zabrocka@e-mail.net.pl
}

\begin{abstract}
This paper outlines a non-destructive method that is suitable for evaluation of condition demonstrated by gas turbine blades and is based on digital processing of images acquired from the blade surface in visible light. To enable high clearness of these images the particular attention is paid to the problem of how to provide optimum conditions for investigations and mitigate geometrical distortions of images acquired from maintenance operations. The paper demonstrates that there are relationships between operation lifetime of blades and discoloration of their surfaces due to overheating of the blade material. These relationships are revealed by digital analysis of images acquired for the blade surfaces and expressed as statistical parameter of the first and second order. To improve unambiguity of the analysis results a low-pass filter was applied. It was demonstrated that these relationships are suitable for evaluation how much the status of the blade material microstructure is altered.
\end{abstract}

Key words: Gas Turbine, Blade, Discoloration, Computer Assistance

\section{INTRODUCTION}

The purpose of the technical diagnostics is to assess machine's elements and their suitability for further work. Assessment of a given detail often does not seem difficult, but the diagnostician must also make a forecast of its status in the proximal and distal lifetime horizon. In the case of non-contact testing occasionally this assessment is based on subjective impressions of the person carrying the inspection. It is a very responsible job because of the need to decide whether a part is still usable. On one hand, a part that could still be used for a long time can be replaced, on the other hand leaving it could lead to a tragic accident caused by wearing of the part (Błachnio and Kułaszka, 2009; Szczepanik and Rzadkowski, 2012). Ability to assess the technical condition of the machine parts by humans depends on many external factors, hence efforts were made to establish objective ways to assess the state of the elements. [Błachnio and Bogdan, 2010; Bogdan, 2009; Żółtowski and Cempel, 2004). The continuous development of digital technology promotes computerization of processes, including the diagnostic process. Developing an algorithm for making decisions on suitability of a given element for work requires a choice in the form of input signals and parameters that are to be analyzed (Bogdan et al., 2009; Pike, 2007; Zieliński, 2005).

The article presents one of the possible ways of evaluating the degree of overheating of the gas turbine blade by image processing of its surface in visible light. As input data of the model, the digital image of the surface of operating gas turbine blades has been selected, and as a result of data processing, numerical information were obtained facilitating objective assessment of the degree of overheating of the blades.

\section{RESEARCH OBJECTS}

Gas turbines are widely used, among others in power plants and heat-power plants or in transportation through water, land and air. The basis of their operation is the process of combustion inherently involving gases of extremely high temperatures affecting in a negative way surfaces of turbine blades (Błachnio and Kułaszka, 2009; Karczewski, 2008; Skočovský et al., 2004).

In order to obtain images of the surface of the gas turbine blades usually optoelectronic devices are used, such as video scopes or video analyzers (Błachnio and Kułaszka, 2009; Rafałowski, 2004). They enable acquiring of images of machine parts with difficult access. Such a device (Fig. 1) consists of a central processing unit, acting as a mobile workstation that allows for management of the collected data, and the inspection probe equipped with a strong light, which is a focused beam of light, making it difficult for even illumination of the shooting area.

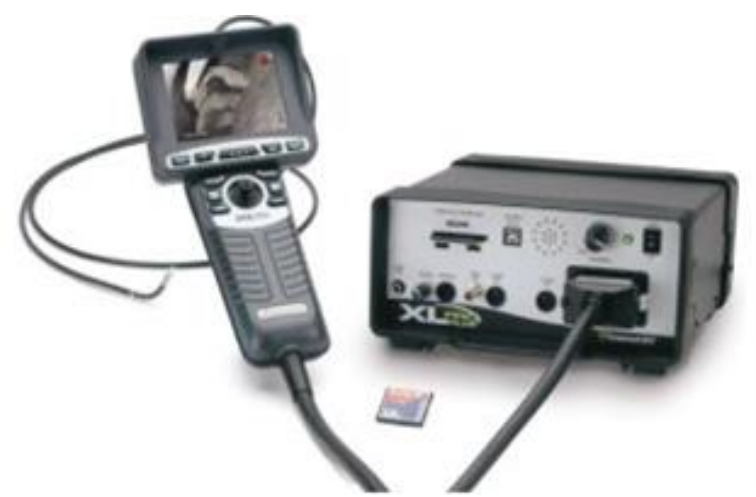

Fig. 1. Optoelectronic device - videoscope

(Błachnio and Kułaszka, 2009)

The acquired images of the gas turbine blade surfaces are stored in the form of a digital image of the RGB colour model in 24-bit mode (Adamczyk and Będkowski, 2005; Watkins et al.,1995; Wróbel and Koprowski, 2004). This format is the basic format of colour images and allows for up to 16777216 colours, as each of the three primary colours ( red, green, blue ) may be of 256 different shades. Any colour can be described by three 
numbers in the range from 0 to 255 . White colour is encoded by three numbers $[255,255,255]$, while black is $[0,0,0]$. This model is mainly applied in televisions, computer screens and digital cameras.

RGB model differs significantly from the way man does it: human technique of colour identification relies on an assessment of their attributes (Doros, 2005; Sankowski et al., 2011). The colour attribute should be understood as a characteristic, intrinsic property that is used to describe one of the three features of a colour: hue (colour, tone) - qualitative difference of a colour, its saturation - colour deviation from whiteness, brightness - indicates whether the colour is closer to white or black.
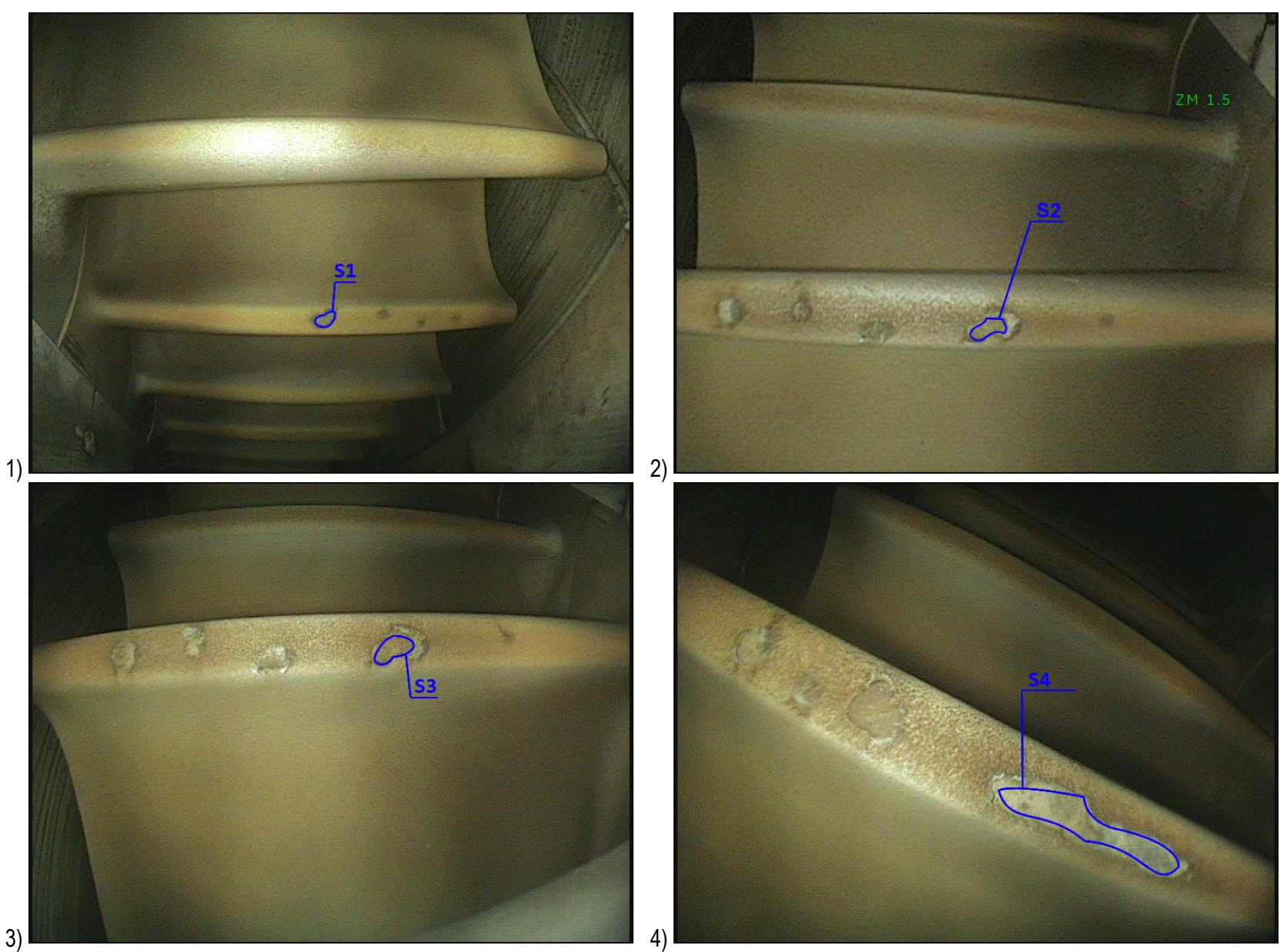

Fig. 2. Photos of a gas turbine blade after successive inspections with marked areas of interest (Spychała et al., 2012)
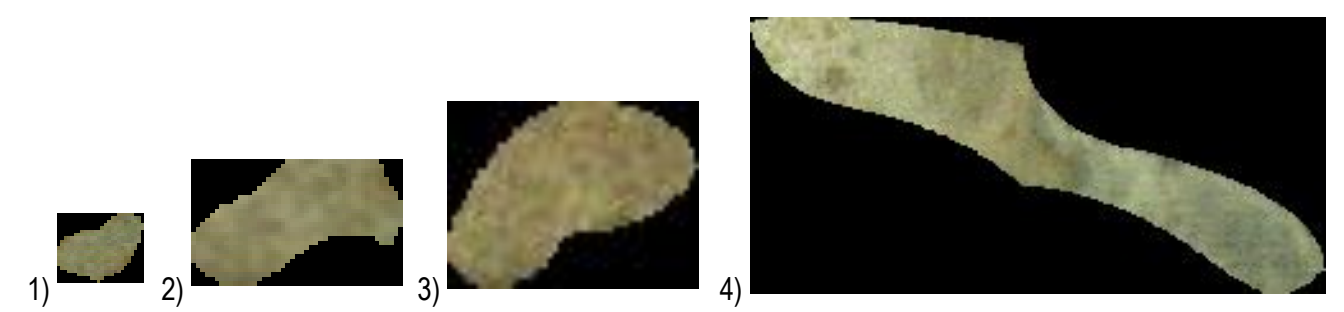

Fig. 3. Analyzed images of the following areas of the blade

The images of exemplary gas turbine blade, obtained by using a videoscope, are shown in Fig. 2. The photos were taken during subsequent inspections of the turbine, with a fixed interval of time between maintenance sessions (Karczewski, 2008; Spychała et al., 2012). In the next stage some interesting images were selected - showing damage to blades, also subsequently analyzed (Fig. 3). Due to the irregular shape of the damaged parts being in focus of examination, they were placed on a black background, so as to form a rectangular image of MxN pixels.

\section{METHODOLOGY OF RESEARCH}

To process and analyse the images Mat lab-based programs were applied. As a result, some parameters were obtained, by means of which an objective assessment of the blade feather was carried out, damaged due to overheating of its material. These parameters were determined on the basis of the histogram distribution of brightness. A histogram is one of the graphical ways of presenting the empirical distribution of characteristics. In the case of a digital image, the histogram shows the frequency 
of occurrence of pixel values. On the x-axis, there are marked successive levels of values of brightness, from 0 , meaning black, to 255 , meaning white. The y-axis, on the other hand, is marked with the quantity of pixels of different brightness values. The histogram may not only be designed for a monochrome image, but also for each primary colour; then zero represents the darkest colour hue, and the number 255 the lightest colour.

The histogram is represented by a vector of length equal to the number of brightness levels of a given image and can be presented as follows (Bogdan, 2009; Watkins et al.,1995; Wróbel and Koprowski, 2004):

$H\left(l_{k}\right)=\sum_{m=1}^{M} \sum_{n=1}^{N} p\left(l_{k},(m, n)\right)$

where: $H\left(l_{k}\right)$ - the total of points at $l_{k}$ - given brightness level, and

$p\left(l_{k},(m, n)\right)= \begin{cases}1 ; & \text { dla } L(m, n)=l_{k} \\ 0 ; & \text { dla } L(m, n) \neq l_{k}\end{cases}$

Additionally, the histogram can be presented in a standardized form, i.e., the one in which each value histogram is divided by the total number of pixels $(M \cdot N)$.

$H_{z n}\left(l_{k}\right)=\frac{\sum_{m=1}^{M} \sum_{n=1}^{N} p\left(l_{k},(m, n)\right)}{M N}$

Statistical parameters of the histogram are:

- medians - the middle element of an ordered set of values tested in ascending order;

- quintiles - elements which are $0 \%$ (the minimum element), $25 \%, 50 \%$ (median), 75\%, 100\% (maximum element) in ascending order set of examined values;

- percentiles - elements of a set of values in ascending order, corresponding to, e.g. $10 \%, 15 \%$, etc.;

Mean value of brightness:

$\mu=\sum_{i=0}^{L-1} \frac{i H(i)}{M N}$

Variation of the brightness distribution:

$\sigma^{2}=\sum_{i=0}^{L-1}(i-\mu)^{2} \frac{H(i)}{M N}$

is a measure of the range of distribution around the mean value; the higher the value, the results are more scattered around the mean.

Skewness of histogram:

$\mu_{3}=\sigma^{-3} \sum_{i=0}^{L-1}(i-\mu)^{3} \frac{H(i)}{M N}$

is indicative of the asymmetry of distribution around the mean value; it provides information about differences between positive and negative deviations from the mean value. Its value equals 0 for symmetric distribution, $\mu_{3}<0$ for the left-asymmetric distribution, and $\mu_{3}>0$ for the right-asymmetric distribution.

Histogram kurtosis:

$\mu_{4}=\sigma^{-4} \sum_{i=0}^{L-1}(i-\mu)^{4} \frac{H(i)}{M N}-3$

(where: $L$ - number of brightness levels, $i$ - brightness level, $H(i)$ - histogram value for a given brightness level, $M N$ - picture resolution) is an indicator of concentration level around mean value, $\mu_{4}<0$ for peaked distribution, $\mu_{4}>0$ for normal distribution.

The use of the algorithm of the main program's function (Fig. 4 ), which is used for image processing, resulted in the deletion of the envelope of histograms and setting the brightness level corresponding to the maximum saturation. Due to the very irregu- lar shape of obtained histograms it was difficult to determine what is the value of brightness occurring with the largest number of pixels in the image. For this reason, filtration was conducted with the use of low-pass filter (Doros, 2005; Pawlak, 2007; Watkins et al., 1995) which was built with blocks available in Simulink (Fig. 5), a part of the MATLAB. As a result of applying this procedure, the effect of smoothing of the histogram graph was achieved (Fig. 6), which allowed for determining of the brightness values attributable to the maximum saturation. A method for obtaining of the value for this parameter represents the diagram in Fig. 7

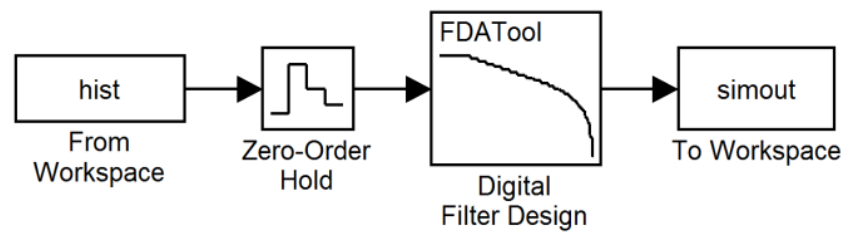

Fig. 4. Algorithm of the main program's function

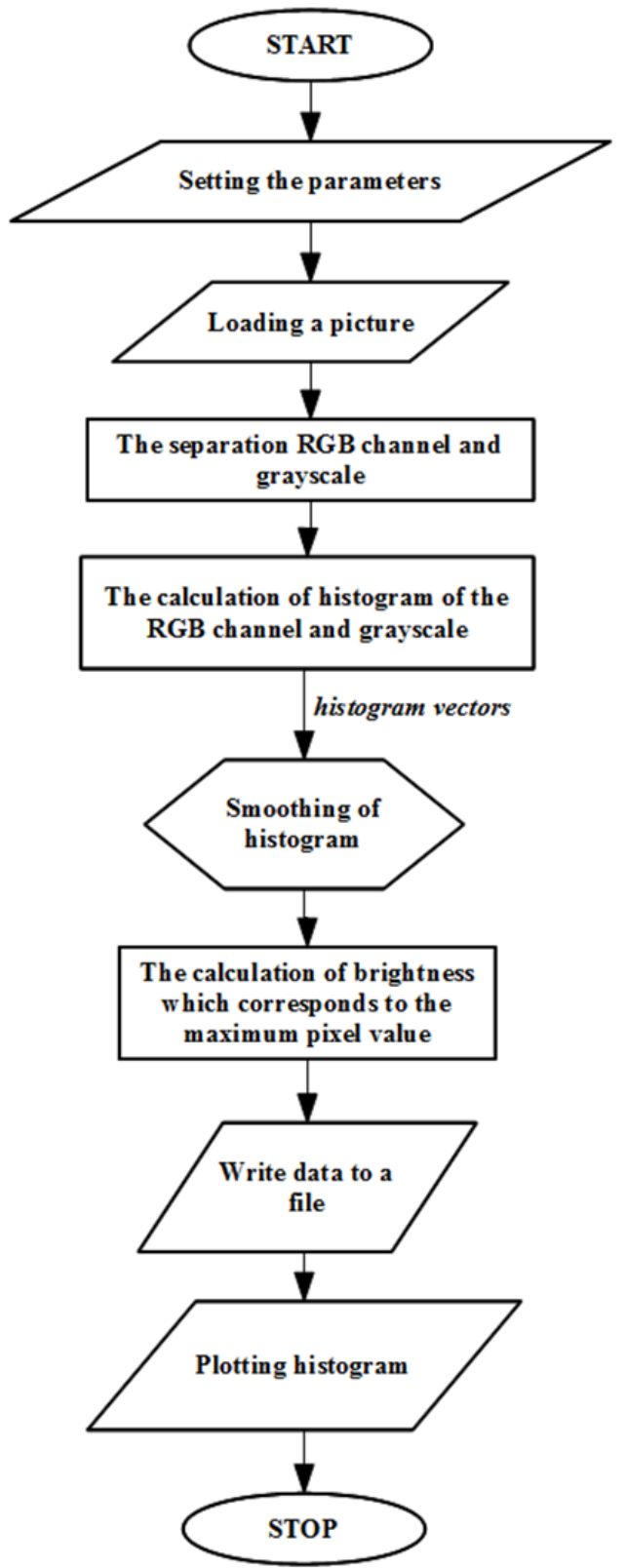

Fig. 5. Block diagram of smoothening subprogram 


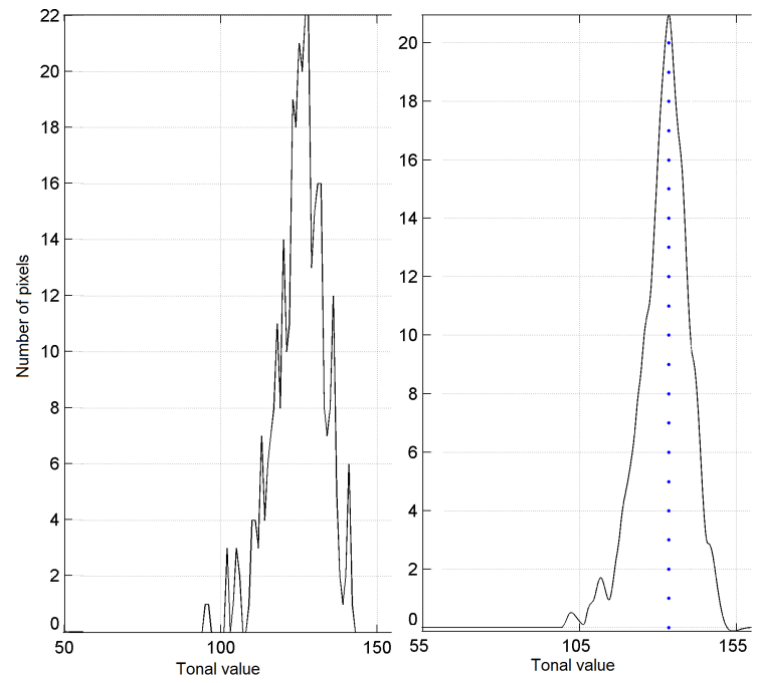

Fig. 6. Exemplary histogram before and after smoothening process

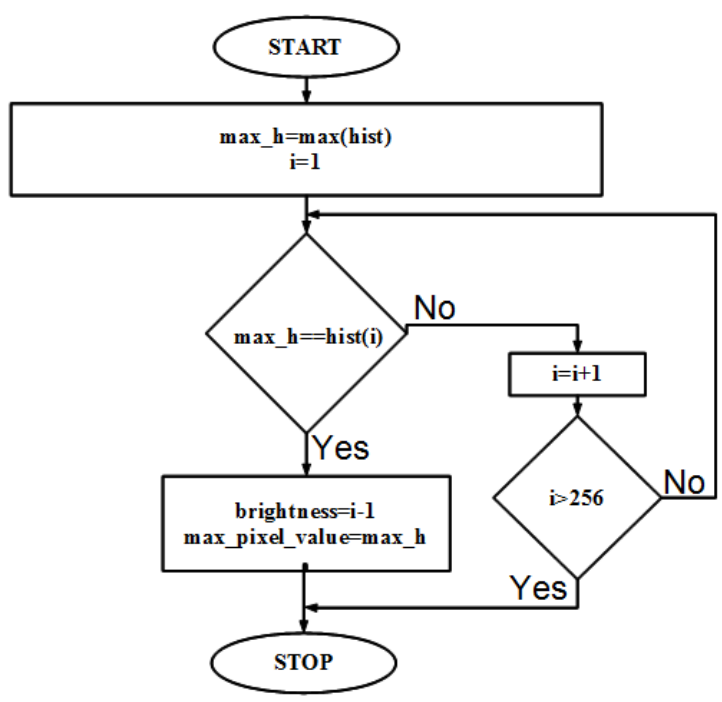

Fig. 7. Schedule of determining the maximum value of the histogram

To calculate the statistical parameters: mean of brightness, variance, skewness and kurtosis a separate program was applied. The method of their determination has been modified so as to prevent added background from generating calculation errors.

The introduced amendment consisted in substituting values into the formulae (4), (5), (6), (7):

- for $M N$ pixels summed up in the program, whose values are different from zero,

- $H(0)=1$, which is resetting the sum of black pixels of the background,

- $(i-1)-\mu$ - Matlab indexes arrays starting at 1 , hence the values corresponding to their own brightness levels are shifted by one.

This procedure resulted in activating the calculation of statistical parameters only for pixels transferring analyzed data.

\section{RESEARCH RESULTS}

Data obtained during the processing of images were placed on graphical charts that illustrate the changing parameters with the duration of the gas turbine exploitation.

Fig. 8 represents graphs showing the progression of the changing position of maximum saturation of operating blades. For monochrome images, the brightness of the areas of damage increases. In the case of RGB colour components, these results are not so obvious, the trend lines set for them have a lower correlation coefficient. Charts with average brightness of the damaged areas are presented in Fig. 9. Runs of average brightness of images are similar in shape to the waveform changes in the position of maximum saturation. Subsequent graphs represent the changes in the variance of the brightness distribution (Fig. 10 ) during the use of gas turbine blades. There was a significant increase in variance value, which means a greater dispersion of the values around the mean brightness of the pixel. Skewness values (Fig. 11) and kurtosis (Fig. 12) do not form a monotonic sequence and also their correlation coefficients carry low values.

a)

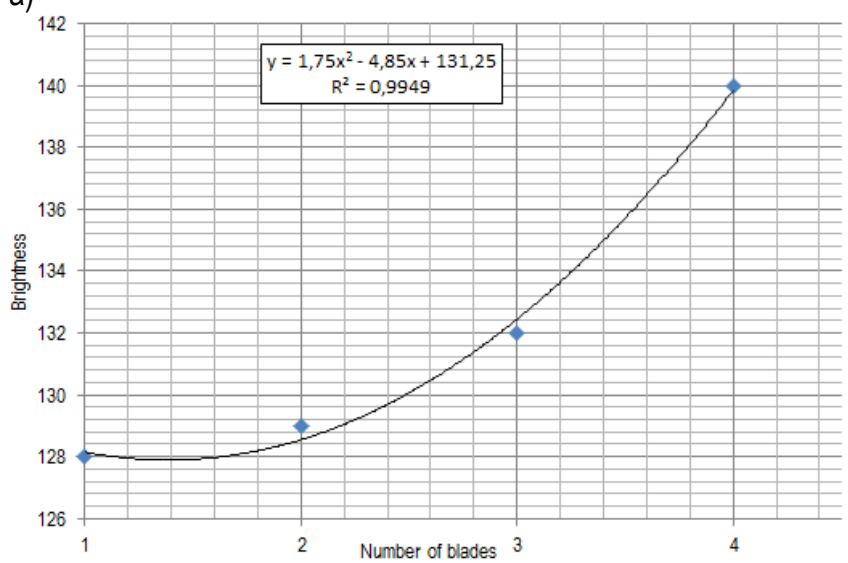

b)

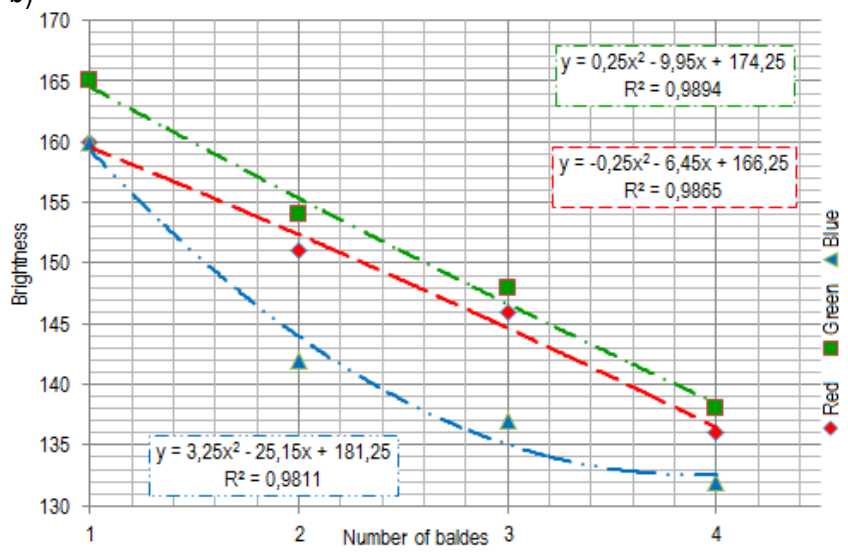

Fig. 8. The brightness values of maximum saturation of areas of interest: a) monochrome images, b) RGB colour components

The shape and size of damages clearly indicate the expansion of their surface as a function of exploitation time. The processing of the images yielded results confirming continuation of destructive effect of high temperature exhaust on the blade material. Values of calculated statistical data for the parts of the first three diagnostic inspections are of comparable size whereas for the fourth area of interest, their increase is much higher (for clarity attributable to the maximum saturation, the mean brightness and the variance), or other sign (for the skewness and kurtosis of the distribution) with respect to others. 


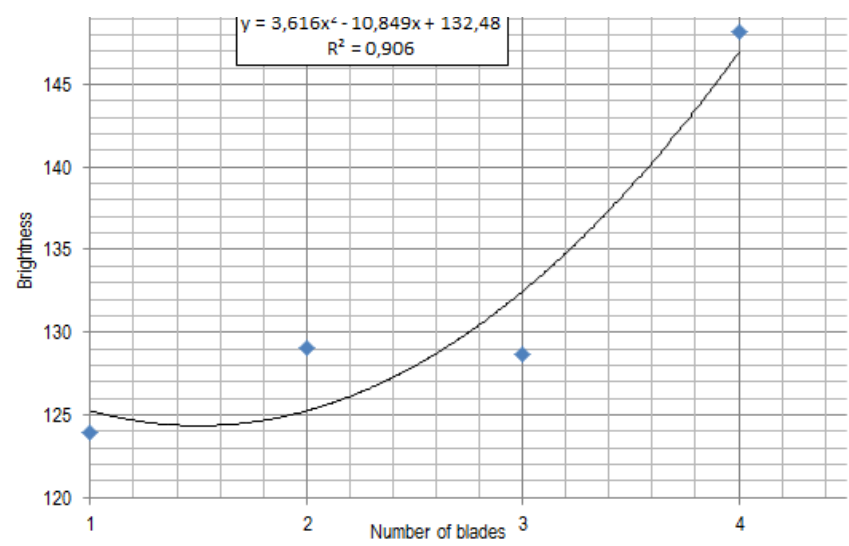

b)

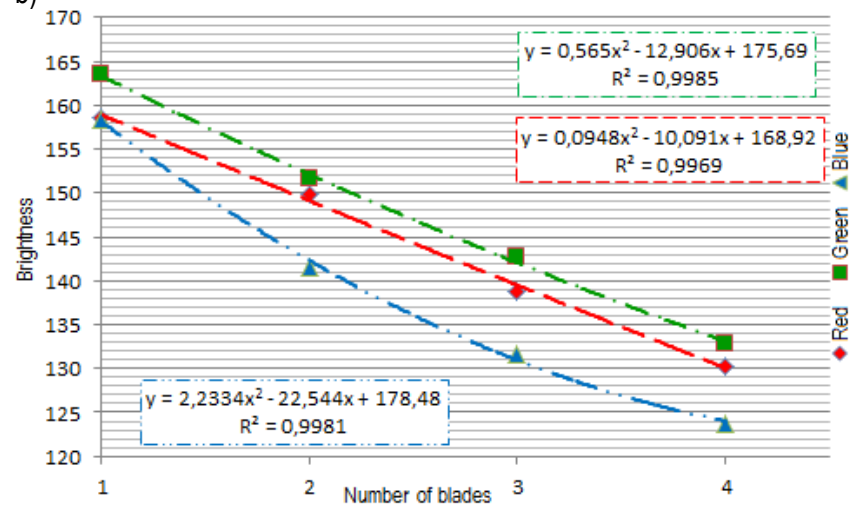

Fig. 9. The average brightness values of maximum saturation of areas of interest: a) monochrome images, b) RGB colour components

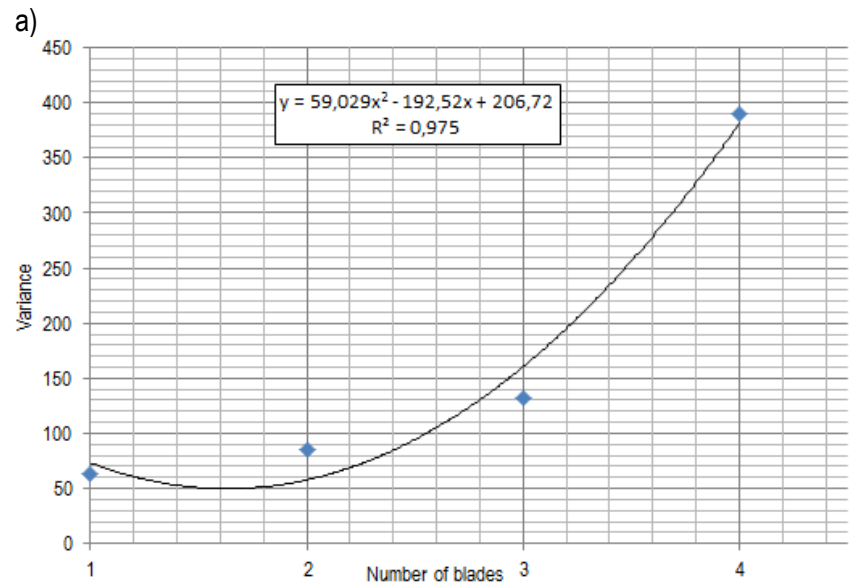

b)

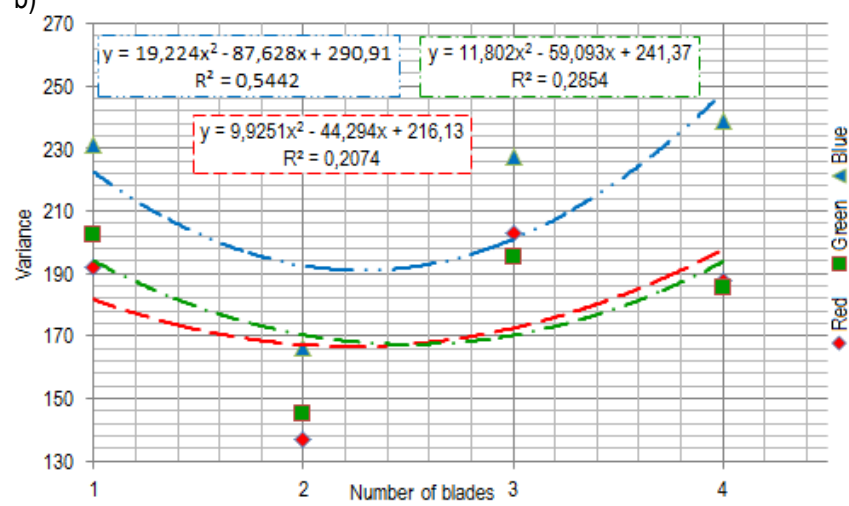

Fig. 10. Variance values for brightness distribution of areas of interest: a) monochrome images, b) RGB colour components

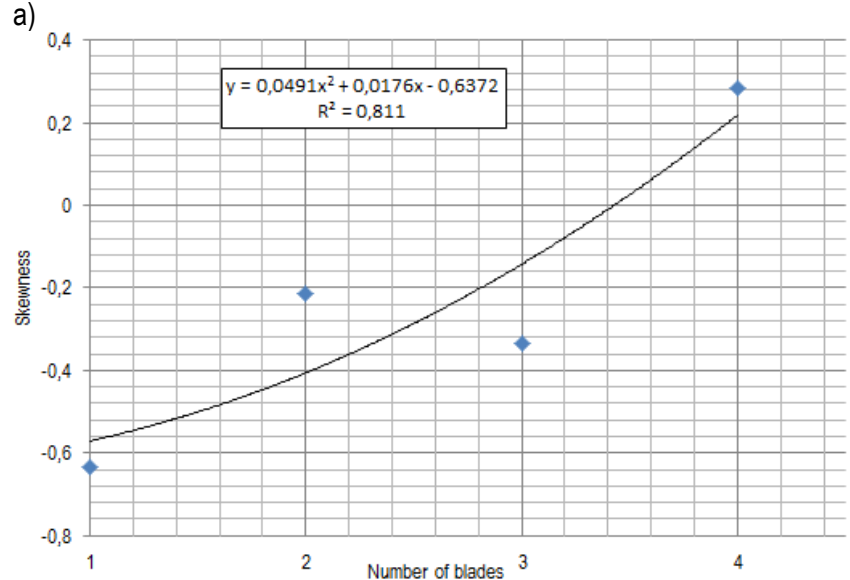

b)

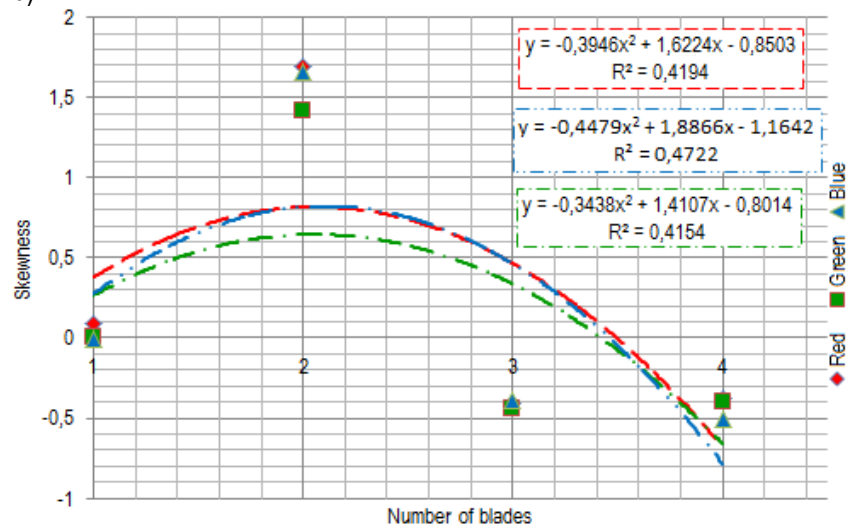

Fig. 11. Skewness values for brightness distribution of areas of interest: a) monochrome images, b) RGB colour components

a)

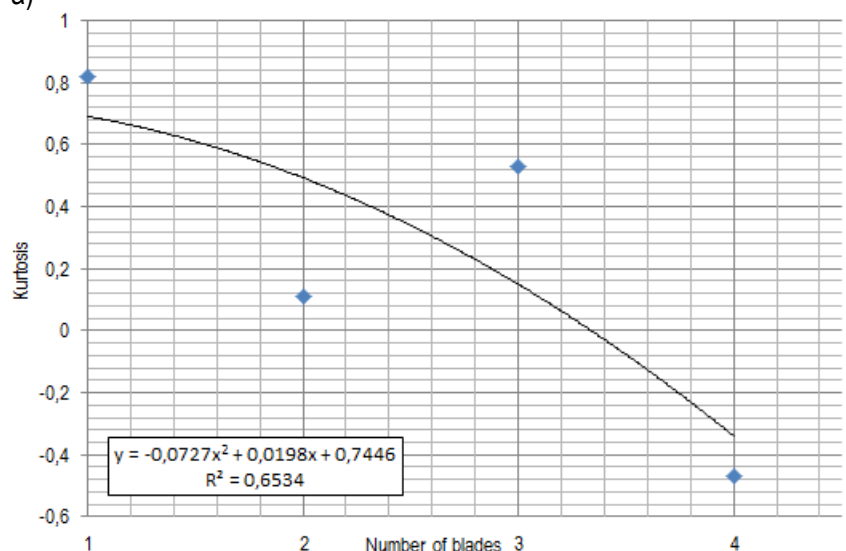

b)

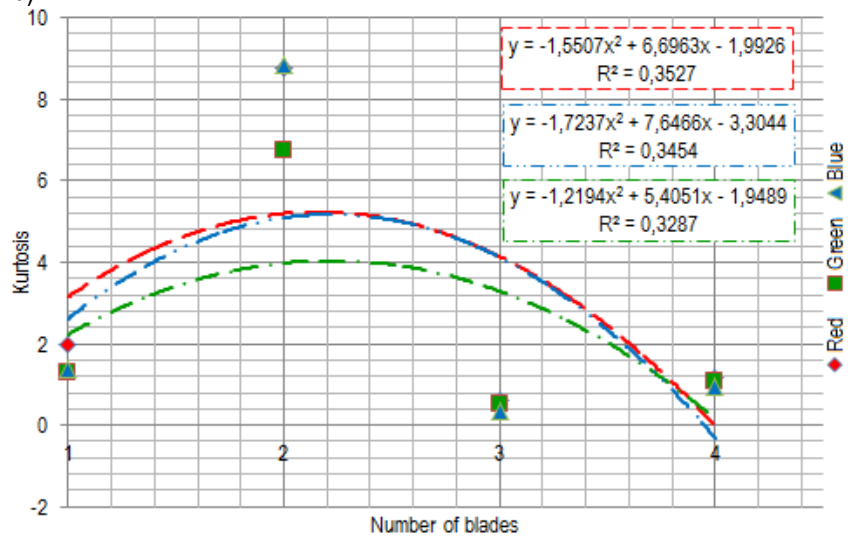

Fig. 12. Kurtosis values for brightness distribution of areas of interest: a) monochrome images, b) RGB colour components 


\section{CONCLUSION}

The operation of gas turbines, like other devices is associated with the occurrence of defects of various character and degree. Due to the conditions in which turbines are operated, the most common faults are blade material overheating and thermal fatigue that are caused by exceeding the limit value for the exhaust gas temperature and its uneven distribution around the circumference of the turbine, all leading to loss of strength of the material. Furthermore, these defects make objective assessment of further ability to use the machine part even more difficult. Since the engine performance depends on the power of the turbine, its efficiency directly affects the power and fuel consumption of the engine. Consequently, the efficiency of the turbine is highly dependent on the temperature of exhaust gas supplied to it. Because gas turbines are commonly applied in power stations and the transport, it is necessary to carry out inspections in which damaged blades are eliminated from operation. However, it is important to bear in mind the fact that not every damage disqualifies a given blade from its further, proper performance. Because of this, an objective, computerized assessment of overheating can optimize the life span of a gas turbine blade.

The research methodology presented in the article is not completely resistant to interference and the results must be correlated with the structural changes of blade material. This should, however, be regarded as a pioneering attempt to develop an algorithm to decide on the suitability or unsuitability of blades for further work. It has been shown that the image of the surface of a gas turbine blade can be used as a diagnostic signal and provide information about its condition, in particular about overheating of the material.

\section{REFERENCES}

1. Adamczyk J., Będkowski K. (2005), Digital methods in remote sensing, SGGW Publishing House, Ed. 1, Warsaw.

2. Błachnio J., Bogdan M. (2010), A non-destructive method to assess condition of gas turbine blades, based on the analysis of bladesurface image. Russian Journal of Nondestructive Testing, Vol. 46, No. $11,860-866$.

3. Błachnio J., Kułaszka A. (2009), Computer aided visual inspection of the technical condition of gas turbine blades during their operation period. Journal of KONES, Vol. 16, No. 3, 23-30.

4. Bogdan M. (2009), Diagnostic investigations of gas turbine blades by digital processing of images acquired for their surfaces, $\mathrm{PhD}$ Thesis, Białystok Technical University, Białystok.

5. Bogdan M., Błachnio J., Derlatka M. (2009), Computer-aided method of diagnostics of gas turbine blades. Acta Mechanica et Automatica, vol 3, no. 4, 13-16.

6. Doros M. (2005), Image processing, Publishing Office of WIT, Warsaw.

7. Karczewski, Z. (2008), Endoscopic diagnostics of marine engines, Diagnostyka, 3(47), pp.19-23.

8. Pawlak W. (1983), The method for compensation of phase lag in analog low-pass filters, Scientific output of the Institute of Aviation, No. 92, Warsaw.

9. Pike L. M., Flower H. L. (2006), Gas turbine superalloy with improved fabricability. Advanced Materials and Processes, ASM International, Vol. 164, No. 6, $39-43$.

10. Rafałowski M. (2004) Integrated image analysers as applied to measurements in lighting technology and to assess shapes of objects, Publishing Office of Białystok Technical University, Białystok.

11. Sankowski D., Mosorov V., Strzecha K. (2011), Industrial systems dedicated image processing and analysis, Polish Socientific Publishers, Warsaw.

12. Skočovský P., Podrábský T., Belan J. (2004), Operational degradation of aluminium-silicone layer of turbine blades made from Ni-based alloy, The Archive of Machinery Technology and Automation, Vol. 24, No. 1, $45-52$.

13. Szczepanik R., Rządkowski R. (2012), A study on the Dynamics of aero enkine blades under different operating conditions, Air Force Institute of Technology, Warsaw.

14. Spychała J., Szczepankowski A., Kułaszka A., Sujka W. (2012), Report No23/34/2012, Air Force Institute of Technology, Warsaw.

15. Watkins C. D., Sadun A., Marenka S. (1995), Modern methods for image processing, WNT Publishing House, Warsaw.

16. Wróbel Z., Koprowski R. (2004), Practice in image processing within the MATLAB software, EXIT Academic Publishing House, Warsaw.

17. Zieliński T. P. (2005), Digital signal processing - from theory to practice, Transport and Communications Publishers, Warsaw.

18. Żółtowski B., Cempel C. (2004), Machinery fault diagnosis engineering, Polish Sosiety of Engineering Diagnosis, Warsaw. 